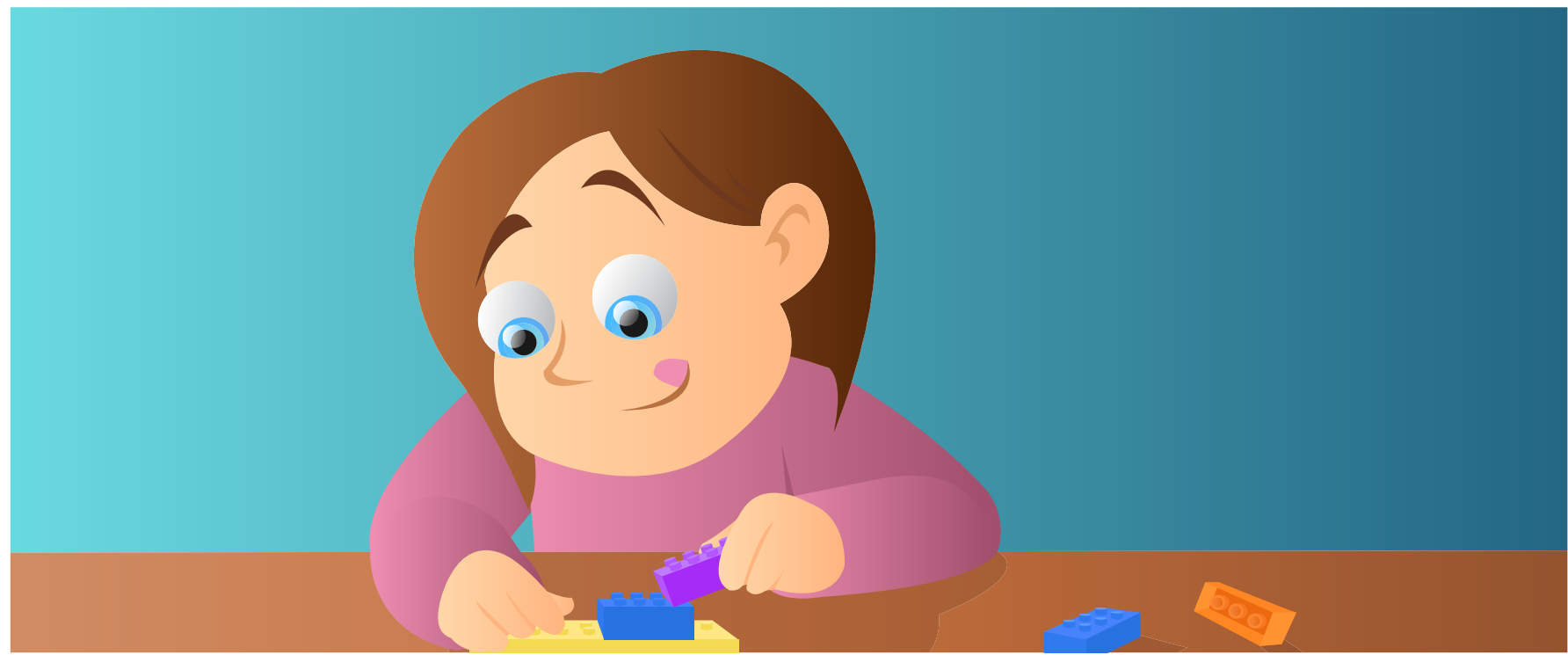

\title{
HOW IS BUILDING LEGO MODELS RELATED TO
}

\section{MATH SKILLS?}

\section{Swiya Murti* and Denes Szucs}

Centre for Neuroscience in Education, Psychology, University of Cambridge, Cambridge, United Kingdom

\section{REVIEWED BY:}

SYDNEY

13 YEARS OLD
Math is usually taught using a lot of words. But, is this the way the human brain learns math? We studied how math is related to memory, intelligence, and reading in 7-year-old children. We found that memory for visual information (things you can see) and spatial information (where things are located in relationship to each other) is related to math skills more than memory for words and verbal information. Interestingly, previous studies have found that building Lego models (construction play) by following instructions is related to math skills. This study found that the relationship between construction play and math is influenced by memory for visual and spatial information. The results of this study make us wonder if building Lego models could improve the brain processes needed for learning math!

\section{WHY WE DID THE STUDY}

To answer the question "How is building Lego models related to math skills?" we first need to figure out which brain processes are involved in learning math. We do this by testing if certain skills and abilities like general intelligence and memory are related to how well children do in math. These skills and abilities are called variables because they change based on 
their relationship with each other. For example, we expect children with higher levels of general intelligence and memory to do better at math, than children with lower levels. The variables we tested were different types of memory (please see Box 1) and general intelligence in 7-year-old children, and we compared their relationship to math and reading.

After discovering the brain processes involved in learning math, we need to find out whether building Lego models is related to learning math and how. Building Lego models, using wooden blocks, sand, and other such toys and equipment to create something is called construction play. While previous studies have found a relationship between construction play and math, these studies do not tell us the brain processes involved in how construction play and math are related. We tested whether the variables of memory and intelligence are the brain processes involved in the relationship between math and construction play.

The first section of this article explains what researchers already know about math and construction play. The second section explains how we tested math, reading, memory, and intelligence. The third section explains what we found, and finally we discuss what our findings mean to children, students, and teachers of math.

\section{WHAT RESEARCHERS ALREADY KNOW}

Previous studies have tested the relationship between construction play and math skills. One study found that teenagers who built taller block models had better math skills than teenagers whose block models tumbled at a shorter height [1]. Another study found that 3-year-old children who could correctly build a block model by following instructions had better math skills [2]. One more study found that children who built complicated models when they were in preschool (3- to 4-year olds) had better math scores in grade 7 (as 12-year olds) [3]. These studies tell us that building block models by following instructions is related to math skills. However, these studies do not tell us the brain processes involved in the relationship between construction play and math skills. Memory is an important brain function for math skills, and so we decided to focus on different types of memory, to test how memory is related to math skills and construction play.

\section{BOX 1 | DIFFERENT TYPES OF MEMORY}

Memory is a very large topic, and researchers divide the topic of memory to make it easier to study. There is long-term memory, short-term memory, and working memory. Long-term memory allows you to remember information for some time - for a few minutes, or for your whole life. For example, if you are divided into groups and are given a number, you will remember your group number for the entire activity. Or, you will remember your name for a lifetime. Short-term memory stores immediate information and is erased in less than a minute. 


\begin{abstract}
For example, if someone tells you a phone number and you dial it immediately and then forget it. It is more difficult to dial a phone number if a person tells you the whole phone number at once, as opposed to telling you the number in bits and pieces. When you work with shortterm memory, it is called working memory. For example, when you read a sentence, you need to remember the first words in the sentence until you finish reading the end of the sentence. Or else, the sentence will not make any sense!

Some researchers divide short-term memory into verbal memory and visuospatial memory [4]. Verbal memory stores information that is in words and is heard. Visuospatial memory stores information on shapes, colors, and locations and can be seen. When you work with verbal or visuospatial short-term memory, it is called verbal working memory (for example: remembering an entire sentence) or visuospatial working memory (for example: remembering directions given on a map).
\end{abstract}

There is one study that tested the role of verbal short-term memory and spatial skills in the relationship between construction play and math skills. They tested spatial skills by asking participants to guess what shape would be made if paper was folded in a certain way. While they found that construction play was related to math skills through spatial skills, verbal shortterm memory was not involved [5]. We thought it was more important to test visuospatial memory with construction play, because to build Lego models you need to see and place the bricks in the correct positions. We also tested reading skills and intelligence to see if the results we found were specific to math skills, or if their general intelligence explained why some children were better at all variables (math, reading, and construction play) and not only at math. To understand the brain processes involved in the relationship between construction play and math skills, we tested verbal short-term memory and working memory, visuospatial short-term memory and working memory, general intelligence, math skills, and reading skills.

\title{
HOW WE DID THE STUDY
}

We asked 7-year-old students from schools in Cambridgeshire, UK, to volunteer for our study. Of the 66 students who volunteered in our study, 30 were girls and 36 were boys. After the study, students were given gift cards and sweets to thank them for volunteering in our study.

We tested math skills and reading skills using a test named Wechsler Individual Achievement Test-Second UK Edition. The math test had questions that got more difficult, starting with addition, subtraction, multiplication, division, fractions, etc. The reading test had words that got more difficult to read. Students stopped their math and reading tests when the questions were too difficult to answer.

We tested general intelligence using a different test called Raven's Colored Progressive Matrices, made for children. In this test, children choose the missing pieces of puzzles that got more difficult to select. 
We tested memory using another test, called the Automated Working Memory Assessment, on a computer. This memory assessment tested four different types of memory, such as

- Verbal short-term memory: tested by reading a list of numbers, and asking students to repeat them.

- Verbal working memory: tested by reading a list of sentences and asking students to first answer whether each sentence was true or false, and then to repeat the last word of the sentences.

- Visuospatial short-term memory: tested by showing dots on a grid and asking students to point to the location of the dots in the order that they appeared.

- Visuospatial working memory: tested by showing a list of sets of shapes, with one of the three shapes in each set being somehow different from the rest. We then asked students to point to the shape that was different, and then to remember the locations of those shapes.

For all the memory tests, the students moved on to the next level after four correct answers. We stopped the test when the students got three answers wrong.

We tested Lego construction ability by giving instructions and Lego bricks to students. The Lego models got more difficult to construct, and we stopped the test when children were unable to correctly build the model. An example of instructions for Lego construction is shown in Figure 1.

\section{FIGURE 1}

Example of instructions for building Lego models [5].

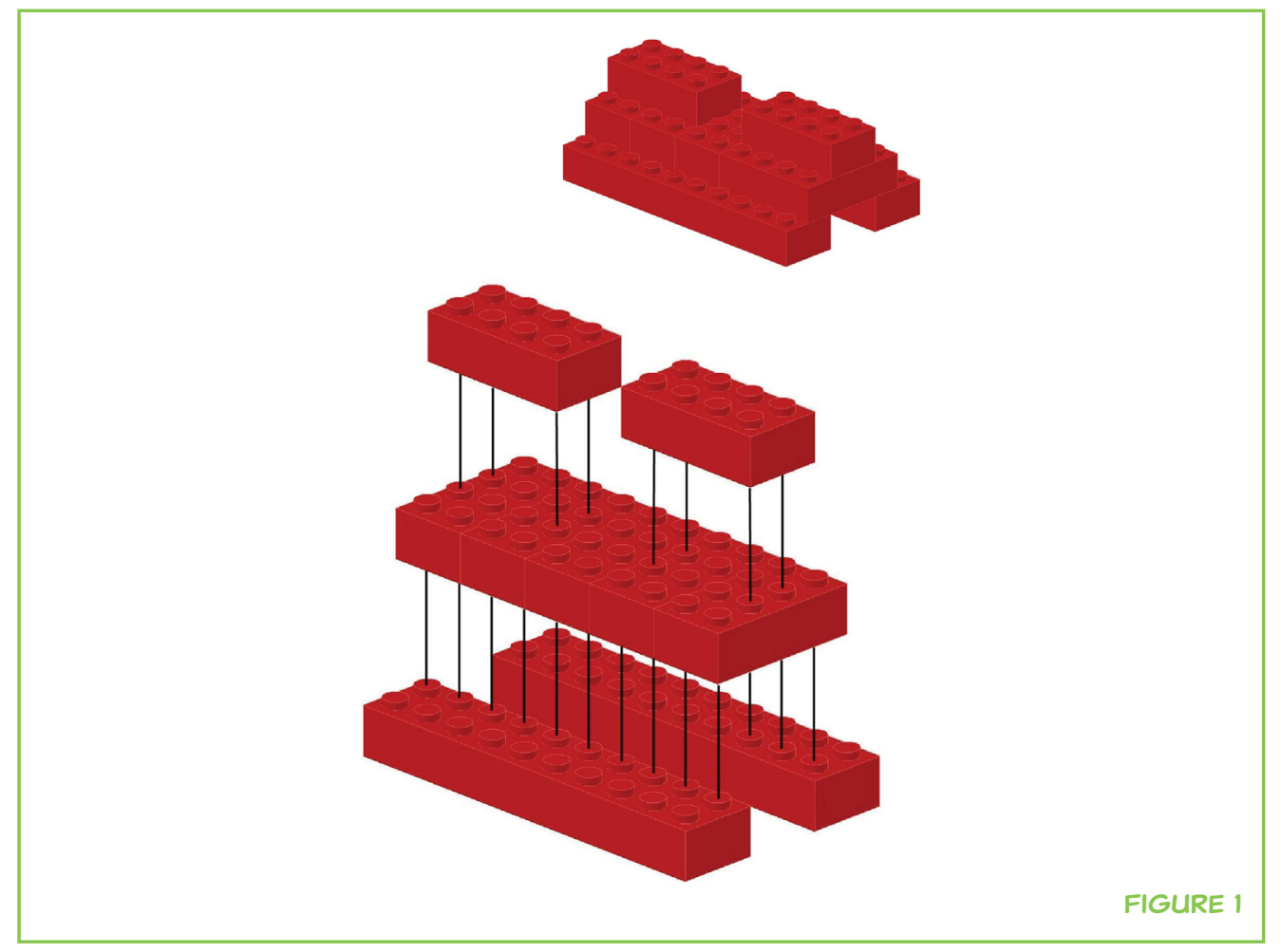


We tested whether the variables (Lego building, memory, intelligence, and reading) were related to math and reading skills using a method called correlation analysis. Correlation analysis tests whether students who did well on the variables also did well in math or reading. Correlation analysis answers the first question of which brain processes are involved with math. To answer the second question of how Lego building is related to math, we used mediation analysis.

Mediation analysis allows us to test if a third variable is involved in a relationship between two variables. For example, let us say a study found an increase in ice cream sales when people go swimming, suggesting that people who like ice cream also like to swim. However, mediation analysis will show us that a third variable is involved. When it is summer, and the weather is hot, people will like to eat ice cream and also go swimming, so the relationship between ice cream sales and swimming is actually caused by hot weather! In the same way, we use mediation analysis to test whether memory or intelligence is the third variable involved in the relationship between construction play and math skills. Children who are good in math may be good at building Lego models. However, what if children with higher intelligence and memory skills are good at both math and construction play?

\section{WHAT THE STUDY FOUND}

We found that math skills were related to reading skills, Lego construction, general intelligence, and visuospatial memory. Interestingly, math skills were not related to verbal memory. Comparing math skills to reading skills, we found that reading skills were related to verbal working memory and math skills only. The results of the correlation analysis with math skills are presented in Table 1.

We tested whether the variables related to math skills (visuospatial shortterm memory, visuospatial working memory, and intelligence) were involved in the relationship between construction play and math skills. The

TABLE 1

Correlation analysis with math skills.
Math skills were related to

- Lego construction

- Visuospatial short-term memory

- Visuospatial working memory

- General intelligence

- Reading

Reading skills were related to

- Verbal working memory

- Math

\section{Math skills were not related to}

- Verbal short-term memory

- Verbal working memory

Reading skills were not related to

- Verbal short-term memory

- Lego construction

- Visuospatial short-term memory

- Visuospatial working memory

- General intelligence 
results from the mediation analysis suggest that visuospatial short-term memory and visuospatial working memory are involved in the relationship between Lego construction and math skills. The relationship between Lego construction and math skills was not because of general intelligence. This means that visuospatial memory plays a unique role in the relationship between Lego construction and math skills, not explained by general intelligence.

\section{WHAT DOES IT ALL MEAN}

The purpose of this study was to understand the brain processes involved in the relationship between construction play and math skills. We first found that the brain processes of visuospatial memory and intelligence were related to math skills, but not to reading skills. Verbal short-term memory was related to reading skills, but not to math skills. Second, we found that construction play is related specifically to math skills, and that visuospatial memory is involved in the relationship between construction play and math skills, not explained by general intelligence.

As we said in the beginning, we are interested in figuring out whether building Lego models might be the secret to improving the brain processes involved in learning math. We found that visuospatial memory is one of the brain process involved in learning math, and that visuospatial memory is involved in the relationship between construction play and math. So, could building Lego models improve a person's visuospatial memory, and therefore increase that person's ability to learn math?

This study can answer the question of which brain processes are involved in the relationship between construction play and math skills. However, it cannot answer the question of whether construction play can improve math skills. We do not know if children who have higher math skills just happen to also have higher construction ability, or if construction play actually improved their math skills. To answer this question, we will need to first test children's construction play skills and math skills, then train some of the children on construction play. If children who get training on construction play improve their math skills more than the children who did not get trained, then we can conclude that construction play can improve math skills.

The take-home message of this study is that visuospatial memory is an important and unique brain process for math skills. Teachers and students should try to use visuospatial memory tools to teach and understand math, instead of only using verbal memory tools. For example, instead of learning the multiplication tables from a chart or from a list of numbers, learning it by placing pebbles in groups may be more helpful in understanding the multiplication tables, and not just memorizing them. 
In conclusion, this study suggests that visuospatial memory, which is a brain process used specifically for math, is involved in the relationship between construction play and math skills and is not explained by general intelligence. With a future study, we can test whether construction play can improve visuospatial memory and math skills in elementary school children.

\section{ACKNOWLEDGMENTS}

This article was originally published in the journal Learning and Instruction (Nath and Szucs, 2014) and has been rewritten for Frontiers for Young Minds. This research was supported by UK Medical Research Council grant (G90951) to DS. Sincere gratitude to Miles Richardson for providing the Lego construction task paradigm instructions. The data were collected with the help of Amy Devine, Alison Nobes, Florence Gabriel, Jacqueline Chung, Jacqueline Ding, and Eleanor Smith.

\section{ORIGINAL ARTICLE REFERENCE}

Nath, S., and Szücs, D. 2014. Construction play and cognitive skills associated with the development of mathematical abilities in 7-year-old children. Learn. Instr. 32:73-80. doi:10.1016/j.learninstruc.2014.01.006

\section{REFERENCES}

1. Casey, B. M., Pezaris, E. E., and Bassi, J. 2012. Adolescent boys' and girls' block constructions differ in structural balance: a block-building characteristic related to math achievement. Learn. Individ. Differ. 22(1):25-36. doi:10.1016/ j.lindif.2011.11.008

2. Verdine, B. N., Golinkoff, R. M., Hirsh-Pasek, K., Newcombe, N. S., Filipowicz, A. T., and Chang, A. 2014. Deconstructing building blocks: preschoolers' spatial assembly performance relates to early mathematical skills. Child Dev. 85(3):1062-76. doi:10.1111/cdev.12165

3. Stannard, L., Wolfgang, C. H., Jones, I., and Phelps, P. 2001. A longitudinal study of the predictive relations among construction play and mathematical achievement. Early Child Dev. Care 167(1):115-25. doi:10.1080/0300443011670110

4. Baddeley, A. 2000. The episodic buffer: a new component of working memory? Trends Cogn. Sci. 4(11):417-23. doi:10.1016/S1364-6613(00)01538-2

5. Richardson, M., Hunt, T. E., and Richardson, C. 2014. Children's construction task performance and spatial ability: controlling task complexity and predicting mathematics performance. Percept. Mot. Skills 119(3):741-57. doi:10.2466/22.24. PMS.119c28z8

SUBMITTED: 20 July 2016; ACCEPTED: 17 May 2017; PUBLISHED ONLINE: 12 June 2017.

EDITED BY: Daniel Ansari, University of Western Ontario, Canada 
CITATION: Murti S and Szucs D (2017) How Is Building Lego Models Related to Math Skills? Front. Young Minds 5:24. doi:10.3389/frym.2017.00024

CONFLICT OF INTEREST STATEMENT: The authors declare that the research was conducted in the absence of any commercial or financial relationships that could be construed as a potential conflict of interest.

COPYRIGHT () 2017 Murti and Szucs. This is an open-access article distributed under the terms of the Creative Commons Attribution License (CC BY). The use, distribution or reproduction in other forums is permitted, provided the original author(s) or licensor are credited and that the original publication in this journal is cited, in accordance with accepted academic practice. No use, distribution or reproduction is permitted which does not comply with these terms.

\section{REVIEWED BY}

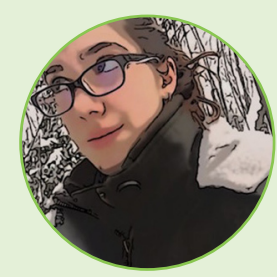

\section{SYDNEY, 13 YEARS OLD}

I am Sydney, I am very interested in writing and editing. I like to learn different things especially when it is related to science. I enjoy reading and writing about a wide variety of topics. Also, I volunteer with teaching young children skating.

\section{AUTHORS}

\section{SWIYA MURTI}

Dr. Swiya Murti's career goal is to research how the human brain learns and the best methods to teach accordingly. Her research work in the Center for Neuroscience in Education, on math development and construction play earned her a Ph.D. from the University of Cambridge, UK. She taught the Human Development and Learning course to

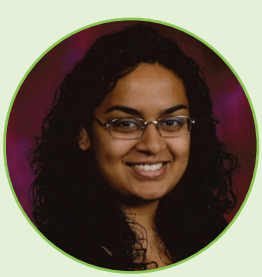
students training to become elementary school teachers at University of Ontario, Institute of Technology. Swiya works with children who have learning disabilities and provides cognitive training at Oshawa Psychological and Counseling Services. *swiyan@gmail.com

\section{DENES SZUCS}

Dénes Szúcs has background in cognitive neuroscience and psychology. He has used electro-encephalography (EEG), electro-myography (EMG), functional near infrared imaging (fNIRS), functional magnetic resonance imaging (fMRI), and behavioral methods. On the one hand, he investigates mathematical understanding and development, mathematics anxiety (including gender differences), dyscalculia, and gifted mathematics. On the other hand, he is very interested in modern research methodology and in the meta-analysis of the published neuroscience and psychology literature. Dénes was the recipient of the prestigious scholar award of the James S. McDonnell Foundation (2013). 